Nanoscale

Aovances

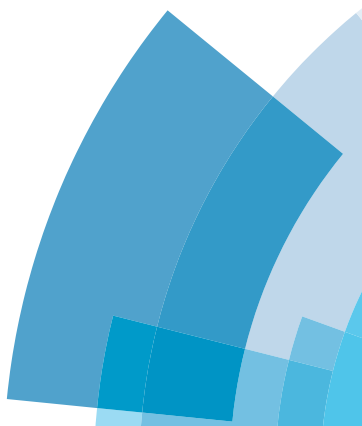

rsc.li/nanoscale-advances

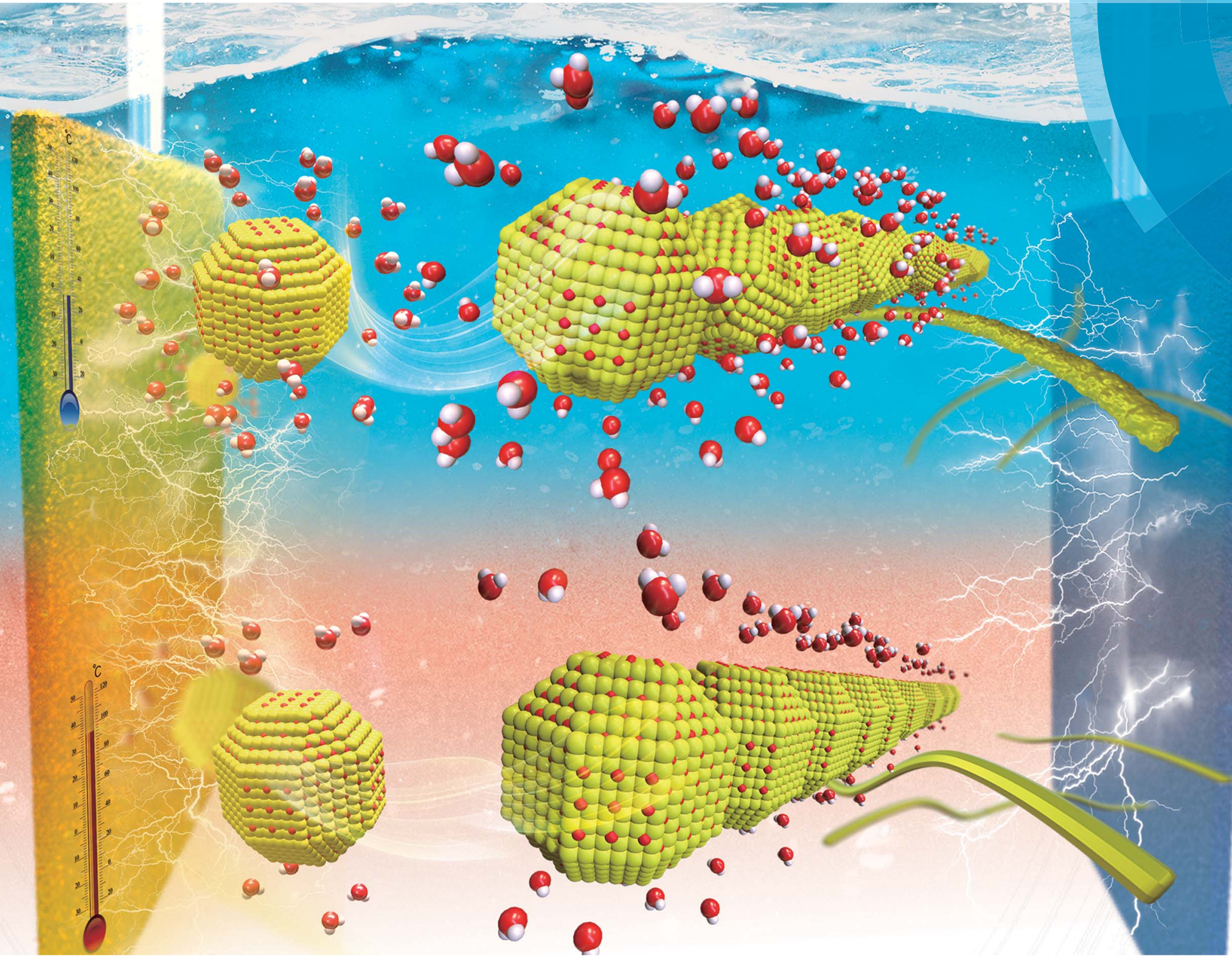

ISSN 2516-0230

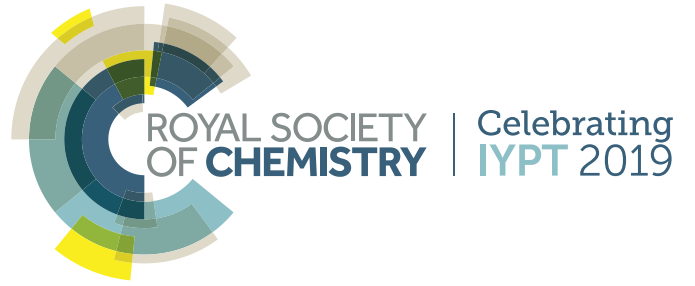


Check for updates

Cite this: Nanoscale Adv., 2019, 1, 2174

\title{
Oriented attachment growth of monocrystalline cuprous oxide nanowires in pure water
}

\author{
Jun Meng, ae Chengyi Hou, (DD*bc Hongzhi Wang, (D) b Qijin Chi, (D) ${ }^{c}$ Yi Gao (D) ad \\ and Beien Zhu*ad
}

As a crucial mechanism of non-classical crystallization, the oriented attachment (OA) growth of nanocrystals is of great interest in nanoscience and materials science. The OA process occurring in aqueous solution with chemical reagents has been reported many times, but there are limited studies reporting the OA growth in pure water. In this work, we report the temperature-dependent OA growth of cuprous oxide $\left(\mathrm{Cu}_{2} \mathrm{O}\right)$ nanowires in pure water through a reagent-free electrophoretic method. Our experiments demonstrate that $\mathrm{Cu}_{2} \mathrm{O}$ quantum dots randomly coalesced to form polycrystalline nanowires at room temperature, while they form monocrystalline nanowires at higher temperatures by the OA mechanism. DFT modeling and computations indicate that the water coverage on the $\mathrm{Cu}_{2} \mathrm{O}$ nanoparticles could affect the particle attachment mechanisms. This study sheds light on the understanding of the effects of water molecules on the OA mechanism and shows new approaches for better controllable non-classical crystallization in pure water.

Received 3rd December 2018

Accepted 24th March 2019

DOI: $10.1039 / c 8 n a 00374 b$

rsc.li/nanoscale-advances science. Various types of external factors that could affect the OA mechanisms have been studied,, 34-20 including adding additives, ${ }^{21}$ changing concentration ${ }^{22}$ and electric field treatment. ${ }^{23}$ Many studies have shown that ligands have a strong influence on the crystal growth process, like some organic molecules $^{24-26}$ and DNA. ${ }^{27,28}$ In these studies, the OA process is mostly reported occurring in chemical solutions, but the OA process in pure water has not been well studied.

Recent studies have proven that adsorbed water molecules not only affect the surface properties of nanostructured materials, ${ }^{29-32}$ but also alter their behaviors such as mobility, shape, and chemical activity in reactions. ${ }^{33-36}$ In particular, Loh et al. have just discovered water-mediated metastable gold complexes during a three-step nucleation process of gold nanocrystals when a supersaturated aqueous solution was used. ${ }^{36}$ Thomele et al. have recently reported that water vapor could induce the self-organization of $\mathrm{MgO}$ nanocubes into one-dimensional crystalline structures. ${ }^{37}$ These results suggest that the water molecules may have a direct impact on nanomaterial crystallization. Thus, studying the OA growth in a pure water environment is of particular interest.

In this work, we firstly synthesized a highly active semiconductor nanocatalyst cuprous oxide $\left(\mathrm{Cu}_{2} \mathrm{O}\right)$ in pure water through a reagent-free electrophoretic method, which can minimize (or exclude) all possible side effects from chemical reagents. In the experiments, $\mathrm{Cu}_{2} \mathrm{O}$ monocrystalline nanowires (MNs) were formed at high temperatures through an OA process (near the water boiling point $90-95{ }^{\circ} \mathrm{C}$ ), while polycrystalline nanowires (PNs) were generated at low temperatures (near the ice point to room temperature). Theoretical analyses show that $\dagger$ Electronic supplementary information (ESI) available. See DOI: $10.1039 / \mathrm{c} 8 \mathrm{na00374b}$ 
the water coverage on the (110) surface of $\mathrm{Cu}_{2} \mathrm{O}$ quantum dots (QDs) decreases sharply by increasing the temperature. It is proposed that the lowered water coverage on $\mathrm{Cu}_{2} \mathrm{O}(110)$ surfaces exposes the (110) facet and makes it a preferable facet for the OA growth of nanowires. This revealed effect provides a novel way to utilize water adsorption for tunable non-classical crystallization.

\section{Experimental}

With the aim of studying the OA process in a pure water environment, the chemical environment should be as simple as possible to avoid any undesirable effects from chemical reagents (e.g., salt precursors, the electrolytic solution, surfactants, buffers, etc.). A reagent-free electrolysis apparatus under the laboratory atmospheric environment was thus used in our experiments (Fig. 1). Briefly, bulk metals were immersed in Milli-Q water $(18.2 \mathrm{M} \Omega \mathrm{cm}$, total organic carbon values $<5 \mathrm{ppb}$, $\mathrm{pH}=6.9$, and redox potential is $10 \mathrm{mV}$ ) with a direct-current electric field applied to the metal electrodes. The target metal (copper in this case) was used as an anode, while Pt was used as a cathode. The gap between the two metal electrodes varied from micrometers to centimeters, resulting in a DC field with an intensity of several volts per centimeter (typically $3-30 \mathrm{~V} \mathrm{~cm}^{-1}$, but not limited to this range). The height of the liquid cell is around 1 centimeter. This strategy is based on our previous innovations. ${ }^{38,39}$ Metal oxide quantum dots (QDs) are generated from the anode upon electrolytic oxidation. The generated QDs undergo electrophoretic assembly during swimming between the two electrodes. $\mathrm{Cu}_{2} \mathrm{O}$ QDs were found to be produced in water around the anode under ambient conditions. ${ }^{38}$ Such nanocrystals are endowed with built-in dipoles under the electric field, and thus are able to assemble into wire-like nanostructures via dipole-dipole interactions. ${ }^{\mathbf{4 0 - 4 2}}$ By altering the water solution temperature (between the ice point and boiling point in order to maintain a liquid cell), the water coverage on QDs can be finely tuned, offering the opportunity for

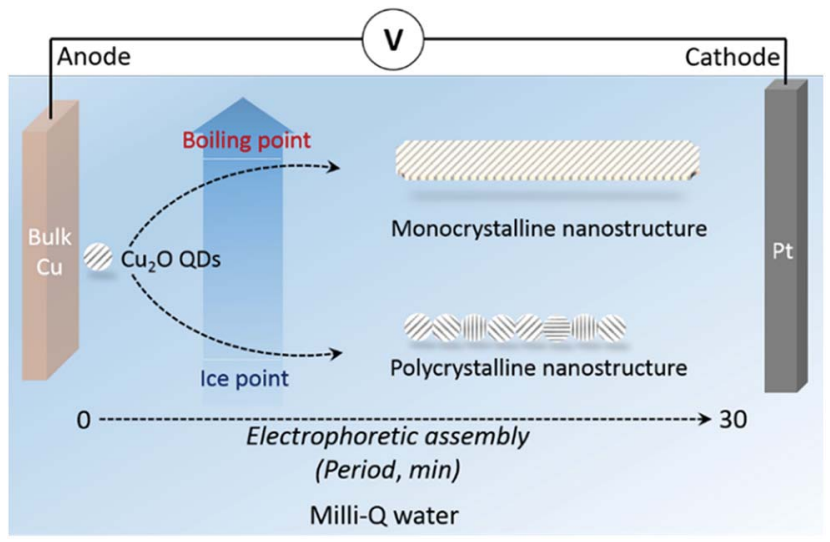

Fig. 1 Schematic of the apparatus used in the reagent-free electrophoretic synthesis of cuprous oxide nanostructures at different environmental temperatures. A 30 min electrolysis period with an applied electric field intensity of $26 \mathrm{~V} \mathrm{~cm}^{-1}$ was typically employed for the synthesis and electrophoretic assembly of cuprous nanowires. investigating the influence of water adsorption on the nonclassical crystallization of metal oxide nanostructures.

The nanostructure formation is captured with the assistance of transmission electron microscopy (TEM) images. The images were taken using a FEI Tecnai T20 G ${ }^{2}(200 \mathrm{kV}$ accelerating voltage; information limit $\sim 0.24 \mathrm{~nm}$ ) and FEI Titan E-Cell 80300 ST TEM (300 kV accelerating voltage; information limit < $0.08 \mathrm{~nm}$ ). It is worth mentioning that in this dynamic electrophoretic system, the nanomaterials simultaneously assemble and swim between the two electrodes, and therefore the location of certain sample groups varies along with the morphology development. ${ }^{38,39}$ Although a real-time and in situ monitoring tool is unavailable, we successfully captured the nanostructure evolution through ex situ TEM imaging. In detail, the suspension containing QDs was collected from the area around the anode after 5 min synthesis. The suspension containing nanowires was collected from the area around the cathode after $30 \mathrm{~min}$.

In control experiments, other variables such as the reaction time (related to morphology development), additional light irradiation (may change the surface properties of semiconductors), and exposure to oxygen (may cause oxidation of cuprous oxide) are regulated carefully. By ruling out the above factors, we focus on one major factor that induces the monocrystalline growth of cuprous oxide nanowires in this work.

\section{Results and discussion}

As shown in Fig. 2a-c, polycrystalline $\mathrm{Cu}_{2} \mathrm{O}$ nanowires that have a length of around 60-100 $\mathrm{nm}$ and a width of approximately $5 \mathrm{~nm}$ were produced at $25{ }^{\circ} \mathrm{C}$. A high-resolution TEM (HRTEM) image regarding the detailed structure of a polycrystalline

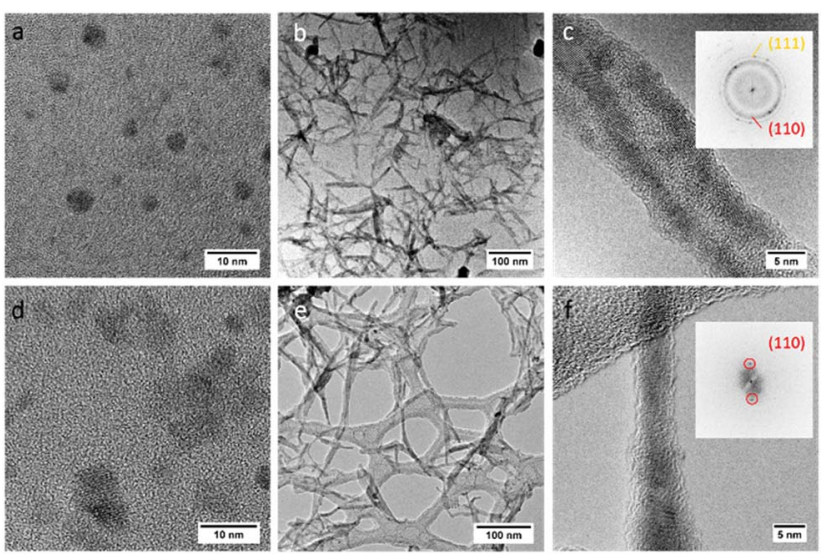

Fig. 2 Microscopic characterization of $\mathrm{Cu}_{2} \mathrm{O}$ nanostructures. (a) HRTEM image of individual $\mathrm{Cu}_{2} \mathrm{O}$ QDs formed at $25^{\circ} \mathrm{C}$. (b) TEM image of $\mathrm{Cu}_{2} \mathrm{O}$ polycrystalline nanowires assembled from QDs at $25^{\circ} \mathrm{C}$. (c) HRTEM image of a single polycrystalline nanowire of $\mathrm{Cu}_{2} \mathrm{O}$ at $25^{\circ} \mathrm{C}$. The inset shows an FFT pattern corresponding to (c). Two major planes (110) and (111) are indicated. (d) TEM image of $\mathrm{Cu}_{2} \mathrm{O}$ QDs synthesized at $90{ }^{\circ} \mathrm{C}$. (e) TEM image of $\mathrm{Cu}_{2} \mathrm{O}$ monocrystalline nanowires grown at $90{ }^{\circ} \mathrm{C}$. (f) HRTEM image of a monocrystalline nanowire of $\mathrm{Cu}_{2} \mathrm{O}$ at $90^{\circ} \mathrm{C}$. The inset shows the FFT pattern of (f). One major plane (110) of cubic $\mathrm{Cu}_{2} \mathrm{O}$ is indicated. 
nanowire (PN) is shown in Fig. 3a and S1. $\uparrow$ The observations of the QDs before the nanowire formation (Fig. 2a) and the lattice fringes shown in Fig. 3a give evidence that the PNs are formed by the attachment of $\mathrm{Cu}_{2} \mathrm{O}$ QDs. X-ray photoelectron spectroscopy (XPS) and electron energy loss spectroscopy (EELS) spectra of the nanomaterials (Fig. S2 and $\mathrm{S} 3 \dagger$ ) confirm the formation of pure $\mathrm{Cu}_{2} \mathrm{O}$. The polycrystalline nature of the assembled $\mathrm{Cu}_{2} \mathrm{O}$ nanowires is confirmed by the fast Fourier transform (FFT) pattern (the inset in Fig. 2c). Moreover, the HRTEM image (Fig. 3a) demonstrates that the PNs have a lattice spacing of 0.25 and $0.22 \mathrm{~nm}$, corresponding to the (111) and (200) planes of cubic $\mathrm{Cu}_{2} \mathrm{O}$, respectively. Apparently, the attachment of $\mathrm{Cu}_{2} \mathrm{O}$ QDs in water proceeded by the RC mechanism at room temperature.

At relatively high temperatures $\left(\right.$ e.g. $\left.90{ }^{\circ} \mathrm{C}\right)$, interestingly, the single crystallization of $\mathrm{Cu}_{2} \mathrm{O}$ nanowires was found to be predominant. As shown in Fig. 2d, the nanoparticle building blocks are no longer monodisperse but coalesced into

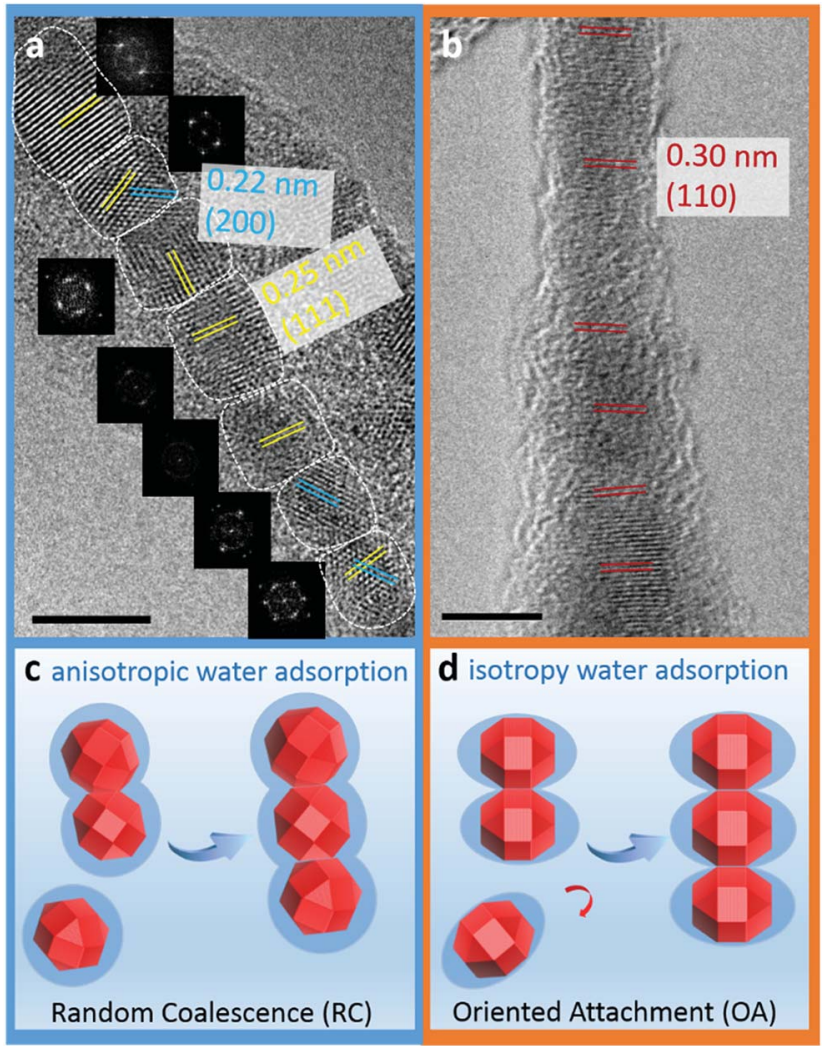

Fig. 3 Detailed structural information of nanowires assembled at $25^{\circ} \mathrm{C}$ and $90^{\circ} \mathrm{C}$ with the proposed formation mechanisms of crystal growth. (a) Detailed information of a typical polycrystalline $\mathrm{Cu}_{2} \mathrm{O}$ nanowire assembled at $25^{\circ} \mathrm{C}$. Individual crystals and their FFT patterns are presented. (111) and (200) planes of $\mathrm{Cu}_{2} \mathrm{O}$ are indicated by yellow and blue lines, respectively. (b) Detailed information of a typical monocrystalline $\mathrm{Cu}_{2} \mathrm{O}$ nanowire synthesized at $90{ }^{\circ} \mathrm{C}$. (110) planes of $\mathrm{Cu}_{2} \mathrm{O}$ are indicated by red lines. A long-range order along the [110] direction in the crystal orientation is visible. (c) Illustration of a random attachment growth pattern of $\mathrm{Cu}_{2} \mathrm{O}$ QDs at room temperature. (d) Illustration of an oriented attachment growth pattern of $\mathrm{Cu}_{2} \mathrm{O}$ QDs along the [110] direction at the higher temperature. Scale bars are $5 \mathrm{~nm}$. nanoparticles mostly composed of two single QDs. Several examples of the initial transient of coalescence of two $\mathrm{Cu}_{2} \mathrm{O}$ nanocrystals are shown in Fig. S4. $\dagger$ After electrophoretic assembly, the $\mathrm{Cu}_{2} \mathrm{O}$ QDs converted to $1 \mathrm{D} \mathrm{Cu}_{2} \mathrm{O}$ nanowires (see XPS results in Fig. S2 $\dagger$ ). Most importantly, these nanowires are well-crystallized monocrystalline nanowires (MNs) and can suspend on a holey carbon support film for recording HRTEM images and corresponding FFT patterns (Fig. 2f, 3b, and $\mathrm{S} 5 \dagger$ ). Preassembled particles, preassembled wires, and well-assembled wires can be observed in a TEM specimen (Fig. S6†). The coexistence of preassembled nanocrystals and nanowires strongly indicates that the long-range ordered MNs are formed via particle attachment, particularly following the OA mechanism. Clearly, the $\mathrm{Cu}_{2} \mathrm{O}$ MNs have a unique ultrathin wire-like morphology. As a comparison, the classic crystallization tends to form cubic-like or sphere-like micro-sized structures. ${ }^{\mathbf{4 3 , 4 4}}$ The interfringe distance of the monocrystalline nanowire is measured to be $0.30 \mathrm{~nm}$, corresponding to the (110) plane of cubic $\mathrm{Cu}_{2} \mathrm{O}$ (Fig. 3b). These planes are slightly misaligned (misoriented by $\sim 3^{\circ}$ as shown in Fig. 3b), as the OA mechanism is the direct coalescence of QDs, and they may keep their initial configurations. Such incorporation of defects (twins, stacking faults, and misorientation) is the important feature of the OA mechanism. ${ }^{\mathbf{4} 45-47}$ All these experimental observations clearly show that the attachment pattern of $\mathrm{Cu}_{2} \mathrm{O}$ QDs switches from $\mathrm{RC}$ to OA by simply tuning the solution temperature, i.e. from a cold water solution to a hot water solution. It should be noticed that the TEM ion-beam induced amorphization of the MN can be seen in Fig. $2 \mathrm{f}$ and $3 \mathrm{~b}$. It is very common that TEM specimens are covered by a (partly) amorphous surface layer due to the exposure to carbon containing molecules during specimen transfer or operating in an imperfect TEM environment. This surface coating has nothing to do with the growth of the MN.

Note that the orientation of $\mathrm{Cu}_{2} \mathrm{O}$ nanocrystals is not under the control of the electric field during the synthesis. Although it is believed that the electric-field-induced dipole-dipole interaction could play an important role in one-dimensional attachment of particles in the electrophoretic assembly, ${ }^{\mathbf{4 0 - 4 2}}$ our results show that the dipole-dipole interaction has very limited effect on particle orientation and crystallization under the present experimental conditions. In this work, the local electric fields are a prerequisite for the construction of a one-dimensional structure of nanowires but not responsible for the different nanowire growth mechanisms at different temperatures.

To understand the $\mathrm{OA}$ growth of $\mathrm{Cu}_{2} \mathrm{O}$ MNs at the higher temperature, we firstly check the TEM images and corresponding SAED patterns of QDs synthesized after $\sim 5 \mathrm{~min}$ at $25{ }^{\circ} \mathrm{C}$, coalesced QDs synthesized after $\sim 1 \mathrm{~min}$ at $90{ }^{\circ} \mathrm{C}$ and further coalesced QDs synthesized after $\sim 5 \mathrm{~min}$ at $90^{\circ} \mathrm{C}$. There is no significant crystallographic structure difference between the QDs synthesized at low temperatures and high temperatures (Fig. S7†). A previous study has reported that, in aqueous solution, hydrated Au atoms have to be partially dehydrated to form nanoclusters. ${ }^{36}$ The water molecules near the small clusters could form a barrier obstructing the further coalescence 
process. In this work, how the water molecules may affect the particle attachment process is evaluated by theoretical calculations. We applied DFT calculations to investigate the interaction between water molecules and different surfaces of the $\mathrm{Cu}_{2} \mathrm{O}$ QDs. There are three types of low-index crystalline facet surfaces on $\mathrm{Cu}_{2} \mathrm{O}$ nanocrystals, i.e., (111), (100) and (110), among which the $\mathrm{Cu}_{2} \mathrm{O}(110)$ surface has the lowest surface energy $\left(0.026 \mathrm{eV} \AA^{-2}\right)^{48}$ and the weakest bonding ability to water molecules (Table 1). The dissociative adsorption of water also has been carefully studied. For the $\mathrm{Cu}_{2} \mathrm{O}(100)$ : O surface, the dissociative adsorption energy is $-0.56 \mathrm{eV}$, which is less stable than the associative adsorption energy $-0.62 \mathrm{eV}$. For the $\mathrm{Cu}_{2}$ $\mathrm{O}(110)$ : $\mathrm{CuO}$ and $\mathrm{Cu}_{2} \mathrm{O}(111)$ : $\mathrm{O}$ surfaces, the $\mathrm{H}$ atom attached to the surface $\mathrm{O}$ atom tends to bond to the surface $\mathrm{OH}$ group and leads to water molecular adsorption. The dissociative adsorption is unfavorable on these surfaces. Based on the previous prediction of the effect of water molecules, we quantify the water coverages on $\mathrm{Cu}_{2} \mathrm{O}$ (111), (100) and (110) facets under our experimental conditions by combining the Langmuir adsorption isotherm and DFT calculations (see the Computational method).

Based on the calculated parameters, the coverages of water on the $\mathrm{Cu}_{2} \mathrm{O}$ surface under the present experimental conditions are plotted against temperatures, and the relationship is shown in Fig. 4. The pressure is $98 \mathrm{~Pa}$ according to the height of water under the experimental conditions calculated using $P=\rho g h(h$ $=1 \mathrm{~cm})$. In the calculations, the temperature changes from 0 to $100{ }^{\circ} \mathrm{C}$. The modelling results provide a reasonable explanation of the experimental results. At $25{ }^{\circ} \mathrm{C}$, the water coverage values on (100), (110), (111) surfaces are all approximately 1 . Individual $\mathrm{Cu}_{2} \mathrm{O}$ QDs coalesce randomly since all the facets are equally protected by the adsorbed water molecules. Fig. 3c displays a sketch describing this process. $\mathrm{Cu}_{2} \mathrm{O}$ QDs may adhere to each other from any crystallographic orientation to form PNs. With the increase of temperature, the water coverage decreases only on the (110) surface. At $90{ }^{\circ} \mathrm{C}$, the water coverage on the (110) surface decreases sharply to 0.21 . The change of water coverage on the $\mathrm{Cu}_{2} \mathrm{O}(110)$ : $\mathrm{CuO}$ surface from $25{ }^{\circ} \mathrm{C}$ to $90{ }^{\circ} \mathrm{C}$ is simulated, and typical images are shown in Fig. 5 according to the results predicted by the theoretical modelling. Without the protection of the adsorbed water molecules, the (110) facets are largely exposed and could promote the directional attachment of QDs, triggering an OA crystallization process as shown in Fig. 3d. As an example, an HRTEM image in the inset of Fig. 4 shows the observed oriented attachment of two $\mathrm{Cu}_{2} \mathrm{O}$ QDs along the $[110]$ direction at $90^{\circ} \mathrm{C}$. This facet-selective particle junction

Table 1 Comparison of the adsorption energy of water molecules on different $\mathrm{Cu}_{2} \mathrm{O}$ surfaces

\begin{tabular}{ll}
\hline & $E_{\text {ads }}(\mathrm{eV})$ \\
\hline$(3 \times 3) \mathrm{Cu}_{2} \mathrm{O}(100): \mathrm{O}$ & -0.62 \\
$(1 \times 1) \mathrm{Cu}_{2} \mathrm{O}(100): \mathrm{O}$ & -0.57 \\
$(3 \times 2) \mathrm{Cu}_{2} \mathrm{O}(110): \mathrm{CuO}$ & -0.36 \\
$(1 \times 1) \mathrm{Cu}_{2} \mathrm{O}(110): \mathrm{CuO}$ & -0.35 \\
$(2 \times 2) \mathrm{Cu}_{2} \mathrm{O}(111): \mathrm{O}$ & -0.81 \\
$(1 \times 1) \mathrm{Cu}_{2} \mathrm{O}(111): \mathrm{O}$ & -0.83
\end{tabular}

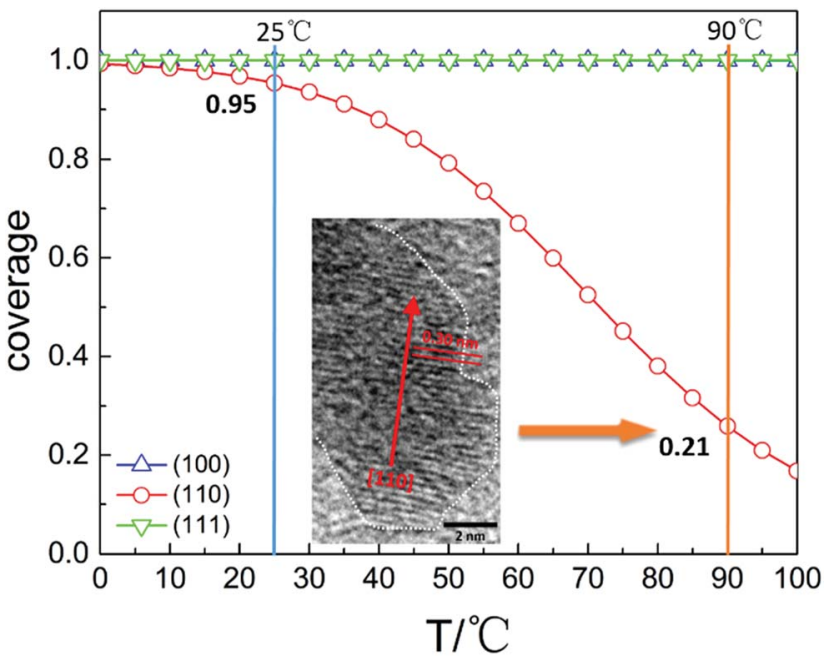

Fig. 4 When $P=98 \mathrm{~Pa}$, the water coverages of $\mathrm{Cu}_{2} \mathrm{O}(100): \mathrm{O}, \mathrm{Cu}_{2}-$ $\mathrm{O}(110): \mathrm{CuO}$, and $\mathrm{Cu}_{2} \mathrm{O}(111)$ : O surfaces vary with the temperature. The inset is a TEM picture of the observed attachment of two $\mathrm{Cu}_{2} \mathrm{O}$ QDs along the [110] direction at $90^{\circ} \mathrm{C}$.

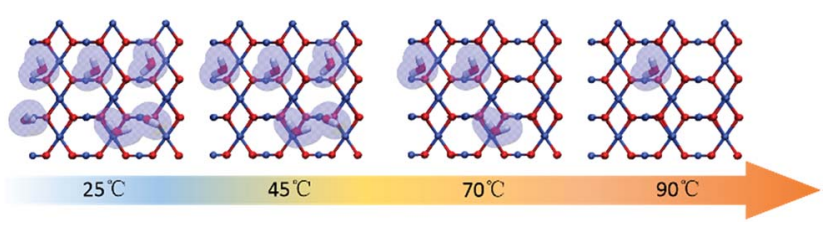

Fig. 5 Simulated images to follow the changes of the water coverage on the $\mathrm{Cu}_{2} \mathrm{O}(110)$ : $\mathrm{CuO}$ surface at $25^{\circ} \mathrm{C}, 45^{\circ} \mathrm{C}, 70{ }^{\circ} \mathrm{C}$ and $90^{\circ} \mathrm{C}$.

results in the well-crystallized $\mathrm{Cu}_{2} \mathrm{O}$ MNs observed in the experiment.

\section{Computational method}

The Langmuir adsorption isotherm ${ }^{49}$ describes the equilibrium surface coverage of the target molecule at a given temperature and under certain pressure by,

$$
\theta=\frac{P K}{1+P K}
$$

where $\theta$ is the surface coverage, $P$ is the pressure, and $K$ is the Langmuir isotherm constant that can be expressed by eqn (2)

$$
K=\exp \left(-\frac{\Delta G}{k_{\mathrm{b}} T}\right)=\exp \left(-\frac{E_{\mathrm{ads}}-T\left(S_{\mathrm{ads}}-S_{\text {liquid }}\right)}{k_{\mathrm{b}} T}\right)
$$

where $k_{\mathrm{b}}$ is the Boltzmann constant, $E_{\text {ads }}$ is the adsorption energy, and $S_{\text {ads }}\left(S_{\text {liquid }}\right)$ is the entropy of adsorbed (liquidphase) water molecules, respectively.

The adsorption energy $E_{\text {ads }}$ of $\mathrm{H}_{2} \mathrm{O}$ molecules on $\mathrm{Cu}_{2} \mathrm{O}$ surfaces is obtained by DFT calculations using eqn (3)

$$
E_{\text {ads }}=E_{\mathrm{H}_{2} \mathrm{O} / \mathrm{slab}}-E_{\text {slab }}-E_{\mathrm{H}_{2} \mathrm{O}}
$$

where $E_{\mathrm{H}_{2} \mathrm{O} / \mathrm{slab}}$ is the total energy of an adsorbed system, $E_{\text {slab }}$ is the energy of a relaxed $\mathrm{Cu}_{2} \mathrm{O}$ slab model and $E_{\mathrm{H}_{2} \mathrm{O}}$ is the energy of an isolated $\mathrm{H}_{2} \mathrm{O}$ molecule. Three low facial index surfaces 
$\mathrm{Cu}_{2} \mathrm{O}(100): \mathrm{O}, \quad \mathrm{Cu}_{2} \mathrm{O}(110): \mathrm{CuO}$, and $\mathrm{Cu}_{2} \mathrm{O}(111): \mathrm{O}$ are modeled to obtain the adsorption energies, which have relatively lower surface energies according to Soon et al. ${ }^{48} \mathrm{~A}(3 \times 3)$ slab for the $(100)$ surface, $(3 \times 2)$ slab for the $(110)$ surface and $(2$ $\times 2)$ slab for the (111) surface are modeled. Each of these slabs contains 5 periodic layers. The 2 bottom periodic layers are fixed and the others are fully relaxed. A vacuum layer of $15 \AA$ is employed to prevent interactions between the repeated slabs. All of the calculations are performed using the Vienna ab initio simulation package (VASP) ${ }^{50}$ with the projector-augmented wave (PAW) potentials ${ }^{51,52}$ and the Perdew-Burke-Ernzerhof (PBE) exchange-correlation functional based on the GGA approximation. ${ }^{53}$ The cutoff energy is selected to be $450 \mathrm{eV}$ and the unit cell lattice parameter is $4.31 \AA$. All the calculations are fully spin polarized. The convergence of the electronic selfconsistent energy is $10^{-5} \mathrm{eV}$, and the force convergence criterion in a conjugate-gradient algorithm is $0.01 \mathrm{eV} \AA^{-1}$. The optimized structures are given in Fig. S9. $\dagger$ The calculated results are compared in Table 1.

Note that the Langmuir isotherm assumes that there is no lateral interaction between the adsorbates. To verify the appropriateness of using the Langmuir isotherm, in this case, the $(1 \times 1)$ slab for each surface is also modeled to obtain the adsorption energy of monolayer water. It is found that there is little difference between the adsorption energy of monomer water adsorption and monolayer water adsorption on the surfaces, indicating negligible lateral interactions (Table 1). Optimized structures are given in Fig. S10. $\dagger$ The $S_{\text {ads }}$ is considered to be zero with the assumption that the adsorbed molecule is isolated and sticks on the adsorption site steadily. The $S_{\text {liquid }}$ can be acquired according to the data from NISTJANAF Thermochemical Tables ${ }^{54}$ (Fig. S11†).

\section{Conclusions}

In conclusion, we report that the OA growth of monocrystalline $\mathrm{Cu}_{2} \mathrm{O}$ nanowires occurs in pure water at elevate temperatures. The experimental findings show a striking crystalline change of the as-synthesized nanowires from the polycrystalline phase to the monocrystalline phase when the water temperature is elevated from 25 to $90{ }^{\circ} \mathrm{C}$ in a reagent-free electrophoretic synthesis. The detailed microscopic analysis and theoretical modeling indicate that the reduced water coverage on the (110) facet of $\mathrm{Cu}_{2} \mathrm{O}$ QDs at $90{ }^{\circ} \mathrm{C}$ facilitates the oriented attachment along the [110] direction. It is suggested that the local water environment could play a key role in determining the attachment pattern of nanoparticles in aqueous solution. In general, this study could offer some crucial clues in uncovering the detailed effects of water on non-classical crystallization such as OA and open a new perspective for ongoing investigations along the related research lines.

\section{Conflicts of interest}

There are no conflicts to declare.

\section{Acknowledgements}

B. Z. thanks the National Natural Science Foundation of China (11604357), the Natural Science Foundation of Shanghai (16ZR1443200), and the Youth Innovation Promotion Association of Chinese Academy of Sciences. Y. G. acknowledges the financial support from the National Natural Science Foundation of China (11574340, 21773287). C. H. acknowledges the Natural Science Foundation of China (51603037) and the Shanghai Natural Science Foundation (16ZR1401500). Q. C. is grateful to the DFF-the Danish Council for Technology and Production Sciences (Project No. 12-127447). The authors thank the Special Program for Applied Research on Super Computation of the NSFC-Guangdong Joint Fund (the second phase). The computational resources utilized in this work were provided by the Shanghai Supercomputer Center, National Supercomputer Centers in Tianjin, Shenzhen.

\section{Notes and references}

1 J. Baumgartner, A. Dey, P. H. H. Bomans, C. Le Coadou, P. Fratzl, N. A. J. M. Sommerdijk and D. Faivre, Nat. Mater., 2013, 12, 310-314.

2 J. F. Banfield, S. A. Welch, H. Zhang, T. T. Ebert and R. L. Penn, Science, 2000, 289, 751-754.

3 J. J. De Yoreo, P. Gilbert, N. Sommerdijk, R. L. Penn, S. Whitelam, D. Joester, H. Z. Zhang, J. D. Rimer, A. Navrotsky, J. F. Banfield, A. F. Wallace, F. M. Michel, F. C. Meldrum, H. Colfen and P. M. Dove, Science, 2015, 349, aaa6760.

4 R. L. Penn and J. F. Banfield, Science, 1998, 281, 969-971.

5 D. Li, M. H. Nielsen, J. R. I. Lee, C. Frandsen, J. F. Banfield and J. J. De Yoreo, Science, 2012, 336, 1014-1018.

6 M. Gong, A. Kirkeminde and S. Ren, Sci. Rep., 2013, 3, 2092.

7 M. P. Boneschanscher, W. H. Evers, J. J. Geuchies, T. Altantzis, B. Goris, F. T. Rabouw, S. A. P. van Rossum, H. S. J. van der Zant, L. D. A. Siebbeles, G. Van Tendeloo, I. Swart, J. Hilhorst, A. V. Petukhov, S. Bals and D. Vanmaekelbergh, Science, 2014, 344, 1377-1380.

8 C. Viedma, J. M. McBride, B. Kahr and P. Cintas, Angew. Chem., Int. Ed., 2013, 52, 10545-10548.

9 B. Y. Xia, H. B. Wu, Y. Yan, X. W. Lou and X. Wang, J. Am. Chem. Soc., 2013, 135, 9480-9485.

10 C. Schliehe, B. H. Juarez, M. Pelletier, S. Jander, D. Greshnykh, M. Nagel, A. Meyer, S. Foerster, A. Kornowski, C. Klinke and H. Weller, Science, 2010, 329, 550-553.

11 Z. P. Zhang, H. P. Sun, X. Q. Shao, D. F. Li, H. D. Yu and M. Y. Han, Adv. Mater., 2005, 17, 42-47.

12 H. Zheng, R. K. Smith, Y.-w. Jun, C. Kisielowski, U. Dahmen and A. P. Alivisatos, Science, 2009, 324, 1309-1312.

13 M. Niederberger and H. Colfen, Phys. Chem. Chem. Phys., 2006, 8, 3271-3287.

14 M. L. Sushko and K. M. Rosso, Nanoscale, 2016, 8, 1971419725. 
15 Z. Zhuang, J. Zhang, F. Huang, Y. Wang and Z. Lin, Phys. Chem. Chem. Phys., 2009, 11, 8516-8521.

16 K. K. Sand, J. D. Rodriguez-Blanco, E. Makovicky, L. G. Benning and S. L. S. Stipp, Cryst. Growth Des., 2012, 12, 842-853.

17 R. P. Sear, Int. Mater. Rev., 2012, 57, 328-356.

18 M. Raju, A. C. T. van Duin and K. A. Fichthorn, Nano Lett., 2014, 14, 1836-1842.

19 C. G. Lu and Z. Y. Tang, Adv. Mater., 2016, 28, 1096-1108.

20 C. Pacholski, A. Kornowski and H. Weller, Angew. Chem., Int. Ed., 2002, 41, 1188-1191.

21 M. Adachi, Y. Murata, J. Takao, J. T. Jiu, M. Sakamoto and F. M. Wang, J. Am. Chem. Soc., 2004, 126, 14943-14949.

22 S. M. Yin, Y. F. Yuan, S. Y. Guo, Z. H. Ren and G. R. Han, CrystEngComm, 2016, 18, 7849-7854.

23 J. Fang, P. M. Leufke, R. Kruk, D. Wang, T. Scherer and H. Hahn, Nano Today, 2010, 5, 175-182.

24 Y. Yin and A. P. Alivisatos, Nature, 2005, 437, 664-670.

25 C. Zhu, S. Liang, E. Song, Y. Zhou, W. Wang, F. Shan, Y. Shi, C. Hao, K. Yin, T. Zhang, J. Liu, H. Zheng and L. Sun, Nat. Commun., 2018, 9, 421.

26 J. M. Yuk, J. Park, P. Ercius, K. Kim, D. J. Hellebusch, M. F. Crommie, J. Y. Lee, A. Zettl and A. P. Alivisatos, Science, 2012, 336, 61-64.

27 L. Zhou, W. Li, Z. Chen, E. Ju, J. Ren and X. Qu, Chem.-Eur. J., 2015, 21, 2930-2935.

28 Z. Chen, C. Liu, F. Cao, J. Ren and X. Qu, Chem. Soc. Rev., 2018, 47, 4017-4072.

29 J. R. Yang, H. P. Fang and Y. Gao, J. Phys. Chem. Lett., 2016, 7, 1788-1793.

30 Y. D. Li and Y. Gao, Phys. Rev. Lett., 2014, 112.

31 M. Farnesi Camellone, F. Negreiros Ribeiro, L. Szabová, Y. Tateyama and S. Fabris, J. Am. Chem. Soc., 2016, 138, 11560-11567.

32 J. Saavedra, H. A. Doan, C. J. Pursell, L. C. Grabow and B. D. Chandler, Science, 2014, 345, 1599-1602.

33 J. Mu, C. Hou, H. Wang, Y. Li, Q. Zhang and M. Zhu, Sci. Adv., 2015, 1, e1500533.

34 B. Zhu, Z. Xu, C. Wang and Y. Gao, Nano Lett., 2016, 16, 2628-2632.
35 P. L. Hansen, J. B. Wagner, S. Helveg, J. R. Rostrup-Nielsen, B. S. Clausen and H. Topsøe, Science, 2002, 295, 2053-2055.

36 N. D. Loh, S. Sen, M. Bosman, S. F. Tan, J. Zhong, C. A. Nijhuis, P. Král, P. Matsudaira and U. Mirsaidov, Nat. Chem., 2016, 9, 77.

37 D. Thomele, G. R. Bourret, J. Bernardi, M. Bockstedte and O. Diwald, Angew. Chem., Int. Ed., 2017, 56, 1407-1410.

38 C. Y. Hou, M. W. Zhang, T. Kasama, C. Engelbrekt, L. L. Zhang, H. Z. Wang and Q. J. Chi, Adv. Mater., 2016, 28, 4097-4104.

39 C. Hou, M. Zhang, L. Zhang, Y. Tang, H. Wang and Q. Chi, Chem. Mater., 2017, 29, 1439-1446.

40 K. D. Hermanson, S. O. Lumsdon, J. P. Williams, E. W. Kaler and O. D. Velev, Science, 2001, 294, 1082-1086.

41 L. Dong, J. Bush, V. Chirayos, R. Solanki, J. Jiao, Y. Ono, J. J. Conley and B. D. Ulrich, Nano Lett., 2005, 5, 2112-2115.

42 A. S. Negi, K. Sengupta and A. K. Sood, Langmuir, 2005, 21, 11623-11627.

43 H. Zhang, Q. Zhu, Y. Zhang, Y. Wang, L. Zhao and B. Yu, Adv. Funct. Mater., 2007, 17, 2766-2771.

44 X. Lan, J. Zhang, H. Gao and T. Wang, CrystEngComm, 2010, 13, 633-636.

45 W. Lv, W. He, X. Wang, Y. Niu, H. Cao, J. H. Dickerson and Z. Wang, Nanoscale, 2014, 6, 2531-2547.

46 H. Zhang and J. F. Banfield, CrystEngComm, 2014, 16, 15681578.

47 J. Zhang, F. Huang and Z. Lin, Nanoscale, 2010, 2, 18-34.

48 A. Soon, M. Todorova, B. Delley and C. Stampfl, Phys. Rev. B, 2007, 75, 125420.

49 I. Langmuir, J. Am. Chem. Soc., 1918, 40, 1361-1403.

50 G. Kresse and J. Hafner, Phys. Rev. B, 1993, 47, 558-561.

51 G. Kresse and D. Joubert, Phys. Rev. B, 1999, 59, 1758-1775.

52 P. E. Blochl, O. Jepsen and O. K. Andersen, Phys. Rev. B, 1994, 49, 16223-16233.

53 J. P. Perdew, J. A. Chevary, S. H. Vosko, K. A. Jackson, M. R. Pederson, D. J. Singh and C. Fiolhais, Phys. Rev. B, 1992, 46, 6671-6687.

54 J. M. W. Chase, C. A. Davies, J. R. Downey Jr, D. J. Frurip, R. A. McDonald, and A. N. Syverud, NIST-JANAF Thermochemical Tables, http://kinetics.nist.gov/janaf/, accessed 09, 2016. 